\title{
Impact on parents of HLA-DQ2/DQ8 genotyping in healthy children from coeliac families
}

\author{
Margreet MS Wessels ${ }^{\star, 1}$, Sabine L Vriezinga ${ }^{1}$, Sybille Koletzko², Katharina Werkstetter ${ }^{2}$, \\ Gemma Castillejo-De Villasante ${ }^{3}$, Raanan Shamir ${ }^{4}$, Corina Hartman ${ }^{4}$, Hein Putter ${ }^{5}$, Sylvia M van der Pal ${ }^{6}$, \\ Cisca Wijmenga ${ }^{7}$, Enzo Bravi ${ }^{8}$ and M Luisa Mearin ${ }^{1}$ on behalf of the PreventCD study group
}

Due to the association of coeliac disease and HLA-specificities DQ2 and DQ8, HLA-typing can be used for risk determination of the disease. This study was designed to evaluate the knowledge of parents from coeliac families regarding HLA-typing and the impact of HLA-typing on the perception of the health of their children. A structured questionnaire was sent to the Dutch, Spanish and German parents participating with their child in the European PreventCD study on disease prevention in high-risk families, addressing parents' understanding of and attitude towards HLA-typing, distress related to HLA-typing and perceived health and health-related quality of life of their children. Sixty-eight percent of parents of 515 children returned the questionnaires, with $85 \%$ of children being DQ2/DQ8 positive. The majority of all parents answered the questions on knowledge correctly. Forty-eight percent of parents of DQ2/DQ8-negative children thought their child could develop coeliac disease. More distress was reported by parents of DQ2/DQ8-positive children $(P<0.001)$. All parents showed few regrets and would repeat HLA-typing in future children. Perceived health and health-related quality of life were similar. In conclusion, we can say that misinterpretation of DQ2/DQ8-negative results by parents is frequent. DQ2/DQ8-positive results do not affect perceived health and health-related quality of life of children but may cause temporary negative feelings among parents. Parents of coeliac families seem to support HLA-typing.

European Journal of Human Genetics (2015) 23, 405-408; doi:10.1038/ejhg.2014.113; published online 11 June 2014

\section{INTRODUCTION}

Coeliac disease $(\mathrm{CD})$ is the most common intolerance to a dietary component in children and adults. ${ }^{1}$ In genetically predisposed individuals, $\mathrm{CD}$ is precipitated by the ingestion of gluten, which are storage proteins in wheat (gliadin), rye (secalin) and barley (hordein). ${ }^{1,2}$ T-cells in the lamina propria of the small intestines recognize the gluten peptides when they are bound to the human leukocyte antigen (HLA) class II specificities DQ2 and/or DQ8 on antigen-presenting cells. ${ }^{2}$ Screening for CD can be done by measuring $\mathrm{CD}$-specific antibodies against the enzyme tissue transglutaminase type 2, endomysium and deamidated gliadin peptides. ${ }^{3} \mathrm{CD}$ is treated with a gluten-free diet. Long-term complications of untreated CD are among others diarrhoea, abdominal pain, perinatal problems, osteoporosis and cancer. ${ }^{1,4}$

CD has a strong genetic component, as $90 \%$ of CD patients carry the class II HLA-DQ2 haplotype, about 5\% the HLA-DQ8 molecule ${ }^{5-8}$ and the rest usually the half of the HLA-DQ2 heterodimer.

The HLA-DQ2 and DQ8 haplotypes are present in over 25\% of the general population, ${ }^{6}$ but only $1 \%$ actually develops CD. ${ }^{1}$ This indicates that HLA-DQ2 and -DQ8 haplotypes are necessary but not sufficient for disease development. Around $40 \%$ of the heritability of CD is explained by HLA-DQ2 and/or -DQ8. First-degree family members of CD patients who are HLA-DQ2 and/or DQ8 positive $(\mathrm{DQ}+)$ have an increased risk of approximately $10 \%$ to develop CD. ${ }^{9}$
Because of the high negative predictive value of HLA-typing for development of CD, unnecessary invasive investigations (ie, blood punctures, duodenal biopsies) in HLA-DQ2 and DQ8 negative (DQ -) individuals can be avoided. Consequently, pediatricians can offer HLA-typing to first-degree family members of a child diagnosed with CD. ${ }^{10}$

Being diagnosed with $\mathrm{CD}$ may have impact on patients' healthrelated quality of life (HRQoL). ${ }^{11,12}$ Currently, concerns are raised about the impact on parents of genetic testing for chronic diseases that only provide a crude estimate of disease risk. It is known that the attitude of parents towards genetic testing for common preventable health conditions in their children is moderately positive. ${ }^{13}$ Unfavourable results may cause parental concerns about the lifelong increased risk for development of CD and the bond between child and parents might be affected with the development of a sense of vulnerability and protectiveness of the child, despite the child's good health. ${ }^{14}$ To our knowledge, the parental impact of HLAtyping for CD risk determination has not been studied. Our aim was to investigate the effect on parents from families with high risk for CD of HLA-typing in their healthy children. We expected parents whose children are $\mathrm{DQ}+$ to take on a more adversary position towards HLA-typing. Subsequently, we hypothesized that parents of DQ+ children will interpret more of their children's symptoms as a sign of $\mathrm{CD}$ and will have a higher rate of health-care utilization.

\footnotetext{
${ }^{1}$ Department of Pediatrics, Leiden University Medical Center, Leiden, The Netherlands; ${ }^{2}$ Department of Pediatrics, Hauner Children's Hospital, Munich, Germany; ${ }^{3}$ Department of Pediatrics, Hospital Universitari de Sant Joan, Reus, Spain; ${ }^{4}$ Department of Pediatrics, Schneider Children's Medical Center, Tel Aviv, Israel; ${ }^{5}$ Department of Statistics, Leiden University Medical Center, Leiden, The Netherlands; ${ }^{6}$ Department of Child Health, TNO, Leiden, The Netherlands; ${ }^{7}$ Department of Genetics, University of Groningen, University Medical Center, Groningen, The Netherlands; ${ }^{8}$ Department of Diagnostics, Eurospital S.p.A, Trieste, Italy

*Correspondence: Dr MMS Wessels, Department of Pediatrics, Leiden University Medical Center, PO 9600, Leiden 2300 RC, The Netherlands. Tel: + 31715269111 ; Fax: + 3171 5248198; E-mail: m.m.s.wessels@lumc.nl
}

Received 5 January 2014; revised 11 May 2014; accepted 15 May 2014; published online 11 June 2014 


\section{SUBJECTS AND METHODS}

For this descriptive study, we took advance of the Dutch, Spanish (Reus) and German cohorts of the ongoing European family study investigating the prevention of $\mathrm{CD}$, PreventCD (www.preventcd.com). The PreventCD study investigates the possibility of reducing the frequency of $\mathrm{CD}$ by introducing small quantities of gluten to infants, between 4 and 6 months of age, preferably while they are being breast-fed. In families with a diagnosed CD member, newborns were HLA-typed shortly after birth, and if they were positive for HLA-DQ2, DQ8 or half of the DQ2 allele, they were considered HLA-DQ + and included in the study (hereafter referred to as PreventCD children). ${ }^{15}$ After informing the parents, the result of the HLA-typing was sent as a letter with an individual risk score: no risk if $\mathrm{DQ}-, 10 \%$ risk if $\mathrm{DQ}+$. In addition, HLA-typing was offered to parents and siblings of the PreventCD children.

For this study, the parents were asked to fill in a questionnaire in their native language after receiving the HLA-typing results. Parents of children who had developed $\mathrm{CD}$ before sending the questionnaire were not invited to participate Parents attending the hospital in Israel with their PreventCD participating children were also asked to complete the questionnaire. As no information could be obtained about the Israeli participation rate, the results on these children and parents were not used in the main analysis.

\section{Questionnaires}

Most questions were weighed on a Likert scale.

Parents' knowledge on HLA-typing for CD was assessed by the following true-false questions: 1. All children who have HLA-DQ2 and/or DQ8 will develop CD (incorrect) and 2. A healthy person can be a carrier of HLA-DQ2 and/or DQ8 (correct). Good knowledge was defined as answering both correctly. To assess parents' understanding of the HLA-typing results of their child, they were asked to evaluate its risk to develop CD.

As there was no HLA-Impact questionnaire available, we constructed one consisting of a form based on validated questionnaires concerning genetic testing for hereditary blood diseases ${ }^{16}$ and cystic fibrosis. ${ }^{17}$ The attitude of the parents towards HLA-typing was evaluated by asking them about the reliability, possible regrets and whether they would consider HLA-typing in case they would have another child. Furthermore, parents rated the information they received on HLA-typing on a scale from 1 ('very bad') to 10 ('excellent'). Parents' behaviour after receiving the HLA-typing results of their children was assessed by the frequency of discussing the results with friends or family and by the methods used to get additional information on HLA-typing, for example, internet, patient association and so on. Parental feelings after receiving the HLA-results were assessed by five questions concerning the degree of worries, anxiety, unhappiness, reassurance, and relieve. A total score reflecting these feelings (min. 0-max. 5, high score indicating positive feelings) was calculated. To assess the parental mood in the week before the questionnaire, we used a four-item Hospital Anxiety and
Depression Scale $(\mathrm{HADS})^{18}$ subscale, a high score corresponding with a positive mood. Internal consistency for all scales was evaluated with Cronbach's alpha.

Perceived health of the children was assessed by questions about the frequency of diarrhoea, vomiting, abdominal distension, constipation and fatigue in their child in the past 3 months. Parents were asked about the concerns about their children's health, and how often their children had been ill in comparison with other children. The health-care utilization was assessed by the frequency of medical visits of the child during the past month. Frequent consultation was defined as $\geq 2$ visits monthly.

HRQoL of the children was evaluated with the validated TNO-AZL Preschool Children Quality of Life Questionnaire (TAPQOL) 43-item version. ${ }^{19}$

\section{Data management and analysis}

Parents in the Netherlands, Spain and Germany received an e-mail with an invitation to participate accompanied by a personal digital code, which gave access to the online questionnaire. A paper version was also available if requested. They were also asked to fill in the questionnaire about their HLAtyped children not participating in PreventCD but only with regard to the child-specific part. The online questionnaire was designed as a web form in a secure data management application ProMISe, (www.msbi.nl/promise), with automatic data export to the Statistical Package for Social Sciences (SPSS) version 20.0 (IBM, New York, NY, USA).

Scale reliability of the HADS items and the negative feelings after receiving the HLA-typing result were calculated with SPSS. For statistical analysis of the HLA-Impact questionnaire, the Pearson's Chi-square test for trend, the unpaired $t$-test, Kruskall-Wallis and Mann-Whitney $U$ test were used where appropriate. For the TAPQOL, a score ranging from 1 to 100 was calculated for every domain, a higher score reflecting a better HRQoL in the relevant scale. ${ }^{19,20}$ Due to abnormal distribution of the TAPQOL results, we used the Mann-Whitney $U$ test for statistical analysis of the results. For each questionnaire item, a difference was found significant if $P<0.05$.

This study was approved by the Medical Ethics Committees of all the participating centers.

\section{RESULTS}

The characteristics of the participating children and parents are presented in Table 1. The age, sex, parent completing the questionnaire, parental educational level and time between receiving the HLA-typing result and completing the questionnaire were similar among the HLA-negative and -positive children (data not shown).

Both parents of DQ + and DQ - children had a good knowledge on HLA-typing in CD (88 and 93\%, respectively), and they found

Table 1 Distribution of characteristics of children and parents and of parental attitude and knowledge of HLA-typing and CD

\begin{tabular}{|c|c|c|c|c|}
\hline & Netherlands & Germany & Spain & Total \\
\hline Children $(n)$ & 214 & 181 & 91 & 486 \\
\hline Participation (\%) & 85 & 62 & 59 & 72 \\
\hline Age children (mean, years) & 3.2 & 4.1 & $5.0 * *$ & 3.8 \\
\hline Sex children (\% male) & 49 & 53 & 52 & 51 \\
\hline Questionnaire filled in by mother (\%) & 88 & 89 & 74 & 86 \\
\hline Educational level of parents, high ${ }^{\mathrm{a}}(\%)$ & 82 & 81 & 65 & 79 \\
\hline Children HLA DQ2 and/or DQ8 positive (\%) & 86 & 80 & 93 & 85 \\
\hline Time between HLA-result and questionnaire (mean, years)** & 2.4 & 2.8 & $4.4^{* *}$ & 2.8 \\
\hline Knowledge of HLA-typing: both questions answered correctly (\%) & $97^{* *}$ & 87 & 92 & 92 \\
\hline No regrets about HLA-typing (\%) & 98 & 100 & 97 & 99 \\
\hline Parents would repeat HLA-typing in future children (\%) & 98 & 97 & 94 & 97 \\
\hline Perception of given information about HLA-typing as good (\%) & 89 & 86 & 67 & 85 \\
\hline Searched for extra information about HLA-typing (\%) & 31 & 38 & 39 & 34 \\
\hline
\end{tabular}

$* * P<0.05$

aDefined as: low - vocational education; intermediate - General Certificate of Secondary Education (GCSE)/A-level; high - (under)graduate/postgraduate. 
HLA-typing a 'reliable' test (88 and 93\%, respectively). However, when asked about the chance of their own child to develop CD according to his/her HLA-typing, $48 \%$ of the parents of the DQchildren thought their child still had a chance to develop CD (Figure 1). There was no correlation between this perception by the parents and their opinion about the reliability of the HLA-test (data not shown).

No parents of DQ - children had regrets about HLA-typing and all of them would perform HLA-typing in their child if they would have one later on. Likewise, almost all parents of DQ + children (99\%) did not regret HLA-typing in their children, and 97\% of them wanted HLA-typing in their child if they would have one in the future. The information about the HLA-typing was similarly appreciated by the parents of $\mathrm{DQ}-$ and $\mathrm{DQ}+$ children with scores of 8.1 and 8.0, respectively, on a $1-10$ scale. The majority of parents found the information on HLA-typing to be 'sufficient, clear and complete' (76 and $87 \%$ of parents of DQ - and DQ + children, respectively). Parents who received unfavourable results looked for more information on HLA-typing (38 vs 17\%, $P=0.01$ ), with the Internet mentioned most frequently. HLA-typing results were discussed equally with family and friends in both groups (57 and 67\% for $\mathrm{DQ}$ - and DQ +, respectively). The knowledge of HLA typing and $\mathrm{CD}$, the attitude towards HLA-typing and the information about it among the different countries is shown in Table 1.

Significantly, more negative feelings were reported by parents who received unfavourable HLA results (mean 3.4, SD 0.9) compared with those receiving favourable results (mean 4.6, SD 0.6) $(P<0.001)$. The German parents experienced more negative feelings than the Dutch and Spanish parents in the same situation (mean score 3.0 (SD 0.8) compared with 3.5 (SD 0.7) and 3.7 (SD 1.0), respectively, $P<0.001$ ). Stressful feelings of the parents at the time of completing the questionnaire were similar, irrespective of the HLA-typing result, (both groups mean score 3.2; SD 0.7 for favourable and 0.5 for unfavourable result), but in Spain, parents receiving unfavourable results reported more stress than parents in the Netherlands and Germany(mean 2.8 (SD 0.6) vs 3.4 (SD 0.5) and 3.1 (SD 0.5), respectively, $P<0.001)$.

Consultation of a doctor in the month before filling in the questionnaire was reported equally among the DQ - (37\%) and $\mathrm{DQ}+(38 \%)$ children, with $8 \%$ reporting a frequent consultation in both groups. The majority of the parents of DQ - (63\%) and DQ+ $(65 \%)$ children found the frequency of illness in their child similar to the one in the general population. However, significantly more

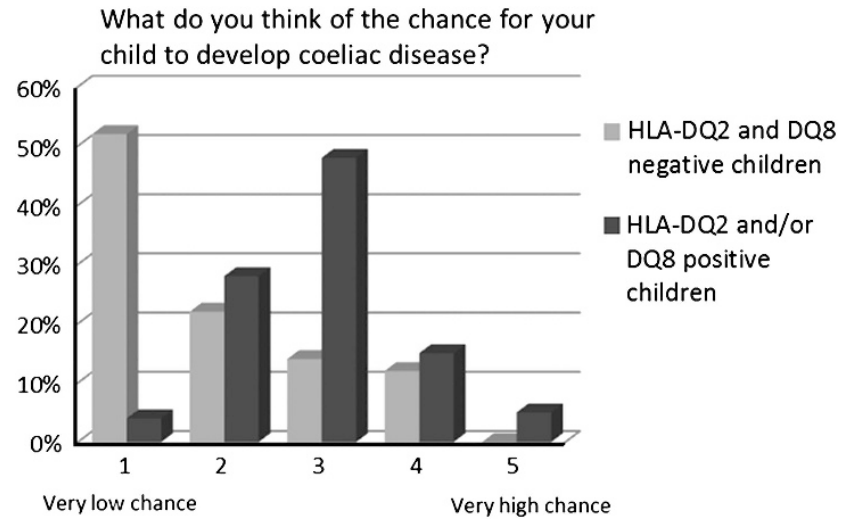

Figure 1 Parental assessment of risk of developing coeliac disease in their child according to HLA-typing results. parents of DQ + children (21\%) had concerns about their children's health compared with parents of DQ - children $(10 \%)(P=0.022)$. When asked about specific health complaints of their children during the 3 months before filling in the questionnaire, these were similarly distributed among the DQ - and DQ + children, with diarrhoea in 42 and $48 \%$, respectively, vomiting in $25 \%$ in both groups, abdominal distension in 19 and 26\%, constipation in 23 and $30 \%$ and fatigue in 25 and $32 \%$, respectively. There were no significant differences between the countries regarding the perceived health of the children by their parents (data not shown).

\section{HRQoL}

This was analysed in 299 children aged 9 months to 6 years using TAPQOL. HRQoL was similar for all domains in the DQ - and $\mathrm{DQ}+$ children with the exception of a lower score in DQ + children with regard to the domain concerning problem behaviour.

\section{DISCUSSION}

The results of this study, the first to assess the impact of HLA typing on families at risk for the development of $\mathrm{CD}$, show a positive parental perception of HLA-typing in their children and that unfavourable results indicating risk for CD do not lead to a lower HRQoL in their offspring. It also demonstrates that despite good knowledge about HLA-typing for CD, almost $50 \%$ of parents of a negative-tested child think that this child has a chance to develop CD. These results are relevant, since over the years, HLA-typing has become more frequently used in the diagnostic process of $\mathrm{CD}$ and it is part of the European Society of Pediatric Gastroenterology Hepatology and Nutrition diagnostic guidelines on CD. ${ }^{10}$

The fact that half of the parents of children who tested negative misinterpreted the results of their child is remarkable, as the majority of these parents knew that their child could not participate in PreventCD due to no risk of CD. This pessimistic interpretation by the parents of a favourable result of genetic testing has been reported before after testing for cancer genes in children. ${ }^{21}$ One explanation could be the failure of adjustment to the sudden removal of the disease scenario, as it has been found in genetic testing for Huntington disease. ${ }^{22}$ The above mentioned misinterpretation of negative HLA findings opens the question whether parents correctly understand the results of HLA-typing for CD and of susceptibility genetic testing in general. ${ }^{23}$ Paradoxical risk interpretation of genetic testing has also been reported in newborn screening for type 1 diabetes, ${ }^{14}$ with $10 \%$ of mothers overestimating or underestimating the risk. It is also known that processing statistical information is often difficult for people and that interpretation of results may be dependent on several factors, such as personal and cultural opinions. ${ }^{24}$ This outcome should prompt physicians to make sure that parents understand the results and to improve the way of giving information to the parents, for example, with a short information brochure about genetic testing. This could be helpful, especially as we found that parents who received favourable results were less inclined to look for additional information on HLA-genotyping and CD.

As expected, parents who received unfavourable HLA results experienced more negative feelings. On the other hand, regrets about HLA-typing were scarce and did not influence the parents' willingness to repeat HLA-typing in future children. Our results show that HLAtyping results do not influence the HRQoL of children as perceived by their parents. However, although the overall concern about the health of their children was low, HLA-positive results lead to more parental concerns in general, not being supported by more health-care utilization or specific health complaints in the DQ + group. 
One possible explanation is that parents in our study are participating in a research project where they are frequently interviewed about the health of their children. Cultural differences with regard to genetic testing did not seem to be taking place, as similar results were seen in the different European countries. Data on parents of 46 children from Israel, who filled in the questionnaires on paper during visits to the hospital, are consistent with this finding. Our study has the strength of novelty and of having been done in a unique, international, prospective cohort of families with high risk of CD. Possible limitations of the study include that the validity of the tools used to assess the parental knowledge of and attitude towards HLA-typing has been not tested in other populations, as they were created for this study. Scale reliability, however, was tested and showed good scores. The question raises whether our group of parents, with a high educational level characteristic for people participating in research projects, is representative for $\mathrm{CD}$ families in general. On the other hand, if high educated parents misinterpreted HLA-typing results, it is likely that $\mathrm{CD}$ parents in general will do so even more. The vast majority of the participating parents were mothers, reflecting their role as being the primary care-givers in most families. Given this fact, we cannot completely exclude that fathers may be less positive than mothers about HLA-typing in CD. As the participating parents in this study were participants in the PreventCD project, one could argue that these parents are mostly people with a positive attitude towards screening for CD and HLA-typing and that our conclusions may not be supported by the parents of CD in general. However, the large size of the PreventCD cohort may be considered as representative for young children from families with high risk for CD. ${ }^{15}$ Our study group also has a relatively small number of DQ - children, but this is characteristic for families with high risk for $\mathrm{CD}$, as shown before. ${ }^{9}$

\section{CONCLUSION}

Parents of CD families support HLA-typing for genetic risk determination for CD. Unfavourable HLA results cause temporary negative feelings in the parents, but no increased health concerns about their children. The interpretation of HLA-DQ2 and/or HLA-DQ8 negative results of their own children is difficult for the parents despite good knowledge of CD and HLA-typing in general. This should urge us to provide parents with good and easy to understand information on this topic.

\section{CONFLICT OF INTEREST}

The authors declare no conflict of interest.

\section{ACKNOWLEDGEMENTS}

Dorine Borensztajn was involved in the design of the study and the development of the questionnaire. Chantal te Marvelde and Els Stoop designed the data collection tools and performed the data management in the database ProMISe. The PreventCD study was funded by the Sixth Framework Programme of the European Commission (FP-2005-FOOD-4B-36383PREVENTCD)

\section{AUTHOR CONTRIBUTIONS}

MMSW monitored data collection for the whole trial, was involved in the development of the questionnaire, cleaned and analysed the data, drafted and revised the paper. SLV implemented the trial and monitored the data collection in The Netherlands, cleaned and analysed the Dutch data and drafted and revised the paper. MLM initiated and designed the project, was involved in the development of the questionnaire, revised the draft paper and coordinated and supervised the project. She is the guarantor. KW, GC-DV, CH, SK and RS implemented the trial in Germany, Spain and Israel and were involved in the preparation of the manuscript. CW and EB performed the HLA-typing and revised the draft paper. SMvdP developed the questionnaire and revised the draft paper. HP was involved in the statistical analysis.

1 Mearin ML: Celiac disease among children and adolescents. Curr Probl Pediatr Adolesc Health Care 2007; 37: 86-105.

2 Green PH, Cellier C: Celiac disease. N Engl J Med 2007; 357: 1731-1743.

3 Rostom A, Dube C, Cranney A et al: The diagnostic accuracy of serologic tests for celiac disease: a systematic review. Gastroenterology 2005; 128(4 Suppl 1) S38-S46.

4 Haines ML, Anderson RP, Gibson PR: Systematic review: the evidence base for long-term management of coeliac disease. Aliment Pharmacol Ther 2008; 28 1042-1066.

5 Sollid LM, Markussen G, Ek J, Gjerde H, Vartdal F, Thorsby E: Evidence for a primary association of celiac disease to a particular HLA-DQ alpha/beta heterodimer. J Exp Med 1989; 169: 345-350.

6 Monsuur AJ, de Bakker PI, Zhernakova A et al: Effective detection of human leukocyte antigen risk alleles in celiac disease using tag single nucleotide polymorphisms. PLOS One 2008; 3: e2270.

7 van Belzen MJ, Koeleman BP, Crusius JB et al: Defining the contribution of the HLA region to cis DQ2-positive coeliac disease patients. Genes Immun 2004; 5: 215-220.

8 Karell K, Louka AS, Moodie SJ et al: Hla types in celiac disease patients not carrying the $D Q A 1 * 05-D Q B 1 * 02(D Q 2)$ heterodimer: results from the european genetics cluster on celiac disease. Hum Immunol 2003; 64: 469-477.

9 Bourgey M, Calcagno G, Tinto N et al: HLA related genetic risk for coeliac disease. Gut 2007; 56: 1054-1059.

10 Husby S, Koletzko S, Korponay-Szabo IR et al: European Society for Pediatric Gastroenterology, Hepatology, and Nutrition guidelines for the diagnosis of coeliac disease. J Pediatr Gastroenterol Nutr 2012; 54: 136-160.

11 van Doorn RK, Winkler LM, Zwinderman KH, Mearin ML, Koopman HM: CDDUX a disease-specific health-related quality-of-life questionnaire for children with celiac disease. J Pediatr Gastroenterol Nutr 2008; 47: 147-152.

12 Rosen A, Ivarsson A, Nordyke $\mathrm{K}$ et al: Balancing health benefits and social sacrifices: a qualitative study of how screening-detected celiac disease impacts adolescents' quality of life. BMC Pediatr 2011; 11: 32

13 Tercyak KP, Hensley AS, Emmons KM, Lipkus IM, Wilfond BS, McBride CM: Parents' attitudes toward pediatric genetic testing for common disease risk. Pediatrics 2011 127: e1288-e1295.

14 Kerruish NJ, Campbell-Stokes PL, Gray A, Merriman TR, Robertson SP, Taylor BJ: Maternal psychological reaction to newborn genetic screening for type 1 diabetes. Pediatrics 2007; 120: e324-e335.

15 Hogen Esch CE, Rosen A, Auricchio R et al: The PreventCD Study design: towards new strategies for the prevention of coeliac disease. Eur J Gastroenterol Hepatol 2010; 22: 1424-1430.

16 Plass AMC, Hemminga M, Westerman M, Cornel MC: Ervaringen van ouders rond de uitslag "drager van sikkelcelziekte" van hun pasgeboren baby naar aanleiding van de per 1 januari 2007 uitgebreide hielprik. TSG 2009; 87: 118-125.

17 Vernooij-van Langen AM, Loeber JG, Elvers B et al: Novel strategies in newborn screening for cystic fibrosis: a prospective controlled study. Thorax 2012; 67 289-295.

18 Zigmond AS, Snaith RP: The hospital anxiety and depression scale. Acta Psychiatr Scand 1983; 67: 361-370.

19 Fekkes M, Theunissen NC, Brugman E et al: Development and psychometric evaluation of the TAPQOL: a health-related quality of life instrument for 1-5-year-old children. Qual Life Res 2000; 9: 961-972.

20 Fekkes MBJ: TAPQOL Manual. Leiden Center for Child Health and Pediatrics LUMC-TNO. 2004. Ref Type: Online Source.

21 Grosfeld FJ, Beemer FA, Lips CJ, Hendriks KS, ten Kroode HF: Parents' responses to disclosure of genetic test results of their children. Am J Med Genet 2000; 94: 316-323.

22 Tibben A, Frets PG, van de Kamp JJ et al: On attitudes and appreciation 6 months after predictive DNA testing for Huntington disease in the Dutch program. Am J Med Genet 1993; 48: 103-111.

23 Michie S, Smith JA, Senior V, Marteau TM: Understanding why negative genetic test results sometimes fail to reassure. Am J Med Genet A 2003; 119A: 340-347.

24 Eiser JR: Communication and interpretation of risk. Br Med Bull 1998; 54 779-790. 